Mateusz Grzeszkowski*, Sebastian Nowoisky, Philipp Scholzen, Gregor Kappmeyer, Clemens Gühmann, Jens Brimmers und Christian Brecher

\title{
Klassifikation von Grübchenschäden an Zahnrädern mittels Vibrationsmessungen
}

\author{
Classification of Gear Pitting Severity Levels using Vibration Measurements
}

DOI 10.1515/teme-2020-0026

Zusammenfassung: In zukünftigen Flugtriebwerken soll ein Planetengetriebe zwischen Fan und Turbine integriert werden, um den Wirkungsgrad und das Nebenstromverhältnis des Triebwerks zu erhöhen. Ein solches Getriebe muss im fortlaufenden Betrieb überwacht werden, um mögliche Getriebeschäden wie Zahnradverschleiß oder Grübchen auf den Zahnradflanken frühzeitig zu erkennen. In diesem Beitrag wird eine Methode vorgestellt, die aus einer Schwingungsmessung, sensorabhängigen Merkmalsgewinnung und einer Support Vector Machine (SVM)-basierten Klassifizierung von Zahnradgrübchen zur Zustandsüberwachung von Getrieben besteht. Mehrere Zahnräder wurden auf einem genormten Zahnrad-Verspannungsprüfstand mit einem konstanten Drehmoment bis zu einer vorgegebenen Grübchenfläche belastet. Die Grübchenfläche wurde begleitend zu den Versuchen fotografisch erfasst. Es wurden Merkmale aus Beschleunigungssensoren und einem Körperschallsensor extrahiert und auf der Grundlage der Ergebnisse der fotografisch erfassten Grübchenfläche wurde ein SVM-Klassifikator entwickelt, um den Grübchenschaden zu identifizieren. Die Ergebnisse zeigen, dass Grübchen ab einer relativen Grübchenfläche am Einzelzahn von weniger als $1 \%$ effektiv identifiziert werden können.

Schlüsselwörter: Grübchen, Klassifikation, Stirnradgetriebe, Support Vector Machine (SVM), Schadensdiagnose.

*Korrespondenzautor: Mateusz Grzeszkowski, Clemens Gühmann, Chair of Electronic Measurement and Diagnostic Technology, Technische Universität Berlin, Einsteinufer 17, 10587 Berlin, E-Mail: mateusz.grzeszkowski@tu-berlin.de, clemens.guehmann@tu-berlin.de

Sebastian Nowoisky, Gregor Kappmeyer, Rolls-Royce

Deutschland Ltd \& Co KG, Eschenweg 11, Dahlewitz, 15827

Blankenfelde-Mahlow, E-Mail:

Sebastian.Nowoisky@Rolls-Royce.com,

Gregor.Kappmeyer@Rolls-Royce.com

Philipp Scholzen, Jens Brimmers, Christian Brecher, Chair of Machine Tools Laboratory of Machine Tools and Production Engineering (WZL), RWTH Aachen, Steinbachstraße 19, 52074 Aachen, E-Mail: P.Scholzen@wzl.rwth-aachen.de, J.Brimmers@wzl.rwth-aachen.de, C.Brecher@wzl.rwth-aachen.de

\begin{abstract}
In future aero engines, a planetary gearbox is to be integrated between fan and turbine to increase the efficiency and bypass ratio. Such a gearbox has to be monitored during operation in order to detect possible gearbox faults such as gear wear or gear pitting at an early stage. This paper presents a method consisting of vibration measurement, sensor-dependent feature extraction and support-vector machine (SVM)-based classification of gear pitting for condition monitoring of gears. Several gears were were loaded with a constant torque on a standardized back-to-back test rig to provoke pitting, and the amount of pitting surface was captured during the tests with a visual recording device. Features were extracted from accelerometers and an acoustic emission sensor, and based on the results of the visually recorded pitting surface, an SVM classifier was designed to identify the pitting defect. The results show that pitting defects with a relative pitting surface of less than $1 \%$ on a single tooth flank can be effectively identified.
\end{abstract}

Keywords: Pitting, classification, spur gearbox, supportvector machine (SVM), fault diagnosis.

\section{Introduction}

In 2019 aviation industry was expected to be growing by $42 \%$ until 2040 compared to 2017 [3]. The current propulsion technology is continuously challenged by the authorities to be even more efficient than today. On a conventional power plant one possible option is to increase the bypass ratio by using a bigger fan. A bigger fan requires a slower fan rotation due to the speed limit at the outer diameter. Therefore a planetary gearbox between fan and turbine is required. This aero engine design allows slow fan rotation together with high turbine speed and as a result, the efficiency and bypass ratio increases significantly. 


\subsection{Power gearbox (PGB) monitoring}

Rolls-Royce demonstrated already the technology of a Power Gearbox (PGB), which is designed as a planetary gearbox and integrated into the novel Rolls-Royce engine family called UltraFan ${ }^{\circledR}$. This UltraFan ${ }^{\circledR}$ engine is capable to provide power up to 75 megawatt [7].

To ensure a reliable functionality of the PGB, suitable sensors are needed to monitor the PGB condition during flight operations. Since vibration measurements offer a sensitive diagnostic indicator with a short response time to gearbox faults, vibration sensors are often used to monitor gearbox condition [11]. But the application of vibration sensors in the PGB will face extraordinary requirements. The sensors must cope with high frequency vibration levels caused by the gear mesh and lower frequency vibration levels caused by the rotating planets, when sensors are located close to the integrated PGB, see figure 1. In addition, the temperature of the oil used to cool and lubricate the gears can exceed $120^{\circ} \mathrm{C}$, which limits the operating time when using active electronics.

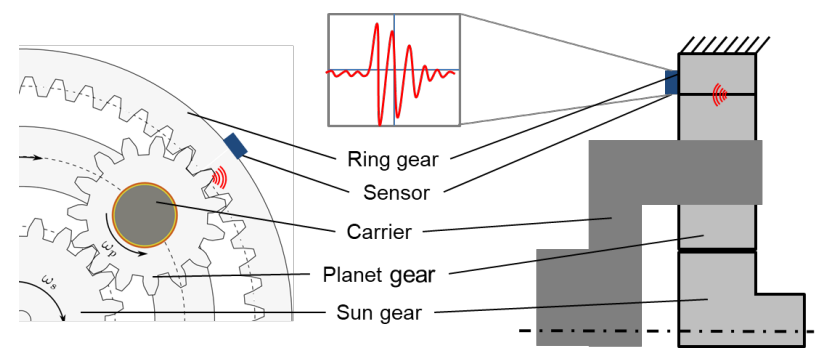

Fig. 1: Planetary gearbox and sensor.

In addition to failure modes such as gear wear or gear tooth cracks, macro-pitting damage can also occur on the tooth flanks of the gears. A macro-pitting damage is characterized by shell-shaped triangular breakouts. Since this failure mode can lead to potentially destructive subsequent damage, great attention is paid to early failure detection of pitting to avoid unplanned engine shutdowns and expensive gear replacements.

\subsection{Diagnosis of macropitting}

There are already various studies that have investigated and discussed the possibilities of detecting gear pitting damage during operation. Tan [8] investigated various measurement techniques and concluded that the acoustic emission (AE) measurement method is suitable for early detection of pitting because a high correlation between
AE amplitude and the pitting fracture zone was observed. Medina [6] performed measurements on a spur gear with artificially induced pitting damage. A deep learning technique based on a long short-term memory network (LSTM) was applied and by means of this method nine degrees of pitting damage could be classified.

In many publications, pitting damage on the tooth flank is artificially induced and the actual pitting progress is rarely captured as an additional pitting size parameter to evaluate diagnostic methods. Therefore, in this contribution natural pitting was provoked on a standardized back-to-back (B2B) test rig and the pitting development was additionally visually captured during the load-capacity tests. Since pitting damage affects the stiffness of the teeth due to changes in the Hertzian contact zone, the vibrations of the gears are altered, which can be measured with accelerometers. On the other hand, cracks at the tooth surface zone lead to excitation of elastic waves in the material, which can be detected with acoustic emission (AE) sensors [8]. Therefore, in this work both sensor technologies are used for pitting detection.

\section{Experimental setup}

In this section the experimental setup will be described. The used B2B test rig and the applied gears are explained as well as the used visual recording device (VRD) to quantify the pitting severity.

The B2B configuration is shown in figure 2 and has a center distance of $112.5 \mathrm{~mm}$. The rig and the operation is standardized according to DIN ISO 14635 [2]. The drive engine speed was set to $\mathrm{n}_{1}=3000 \mathrm{~min}^{-1}$. The used oil has a regulated test temperature of $\mathrm{T}_{\text {Oil }}=90^{\circ} \mathrm{C}$ with sump lubrication. After running-in at a torque of $\mathrm{M}_{\mathrm{in}, 1}=200 \mathrm{Nm}$, all tests are carried out at a test load of $\mathrm{T}_{\text {test }, 1}=650 \mathrm{Nm}$, in order to enable occuring pitting after $\mathrm{N}_{\mathrm{G}}=50 \cdot 10^{6}$ load cycles (L.C.).

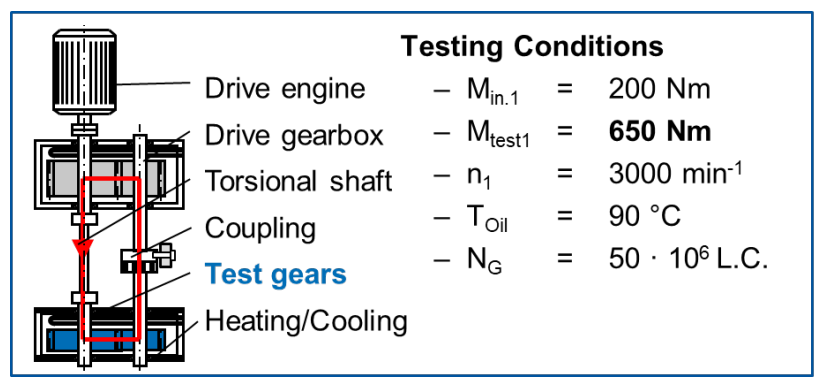

Fig. 2: Back-to-back test rig and testing conditions. 
Two gear sets with same gear geometries and surface properties were manufactured for the experiments. The gear geometry is an established test geometry of type $21 / 23$ with a stepped tooth root according to Tobie [9] and a common tooth width of $b=10 \mathrm{~mm}$ for a secure separation of pitting and tooth root safety regarding the investigation [2].

To obtain a reproducible picture of each pinion teeth a mechanical adapter was built to place a camera on top of the opened B2B rig as shown in figure 3 (left). As a result, geometrically comparable images with similar light properties were generated of each pinion tooth. Image acquisition was performed more frequently towards the end of each test campaign in order to record the pitting progress with increasing pitting damage with a higher time resolution. After test execution, 14 inspections were carried out for the first gear set and 15 inspections for the second gear set.

The pitting severity was quantified using the DOP (degree of pitting severity) value, which is defined as the ratio of the pitted surface area to the entire surface area of the loaded tooth flank. The value was calculated for every $k$-th tooth $\left(\mathrm{DOP}_{k}\right)$ and for all teeth of one gear $\left(\mathrm{DOP}_{G}\right)$. Considering the FVA guideline [10] for load capacity tests the gears were run until condition $\mathrm{DOP}_{k} \geq$ $4 \%$ or $\mathrm{DOP}_{G} \geq 1 \%$ was fulfilled.

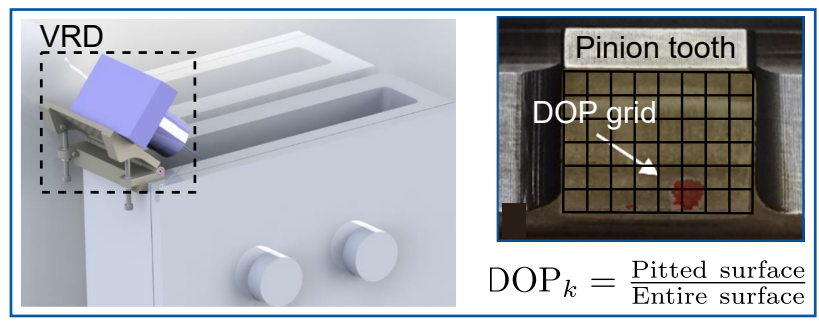

Fig. 3: Visual recording device (VRD) and DOP calculation.

\section{Sensor instrumentation}

With the preliminary considerations the following sensor instrumentation in figure 4 was applied on the B2B gear test rig. One accelerometer was mounted on the bearing shell near the test pinion and another accelerometer was mounted on the housing of the test gears and both were sampled at $200 \mathrm{kHz}$. From investigations already conducted, it is known that pitting initiation process begins with the excitation of high frequency $\mathrm{AE}$ impulses above 50
$\mathrm{kHz}$. Therefore an AE sensor with a bandwidth of $150 \mathrm{kHz}$ was mounted on the bearing shell near the test pinion and sampled with $500 \mathrm{kHz}$. In addition, the instantaneous shaft rotation angle of the torsional shaft was acquired using a high-resolution incremental encoder with an angular resolution of $0.011^{\circ}$. All sensors were recorded synchronously every 10 minutes with a duration of 10 seconds using a multi-channel measurement system.

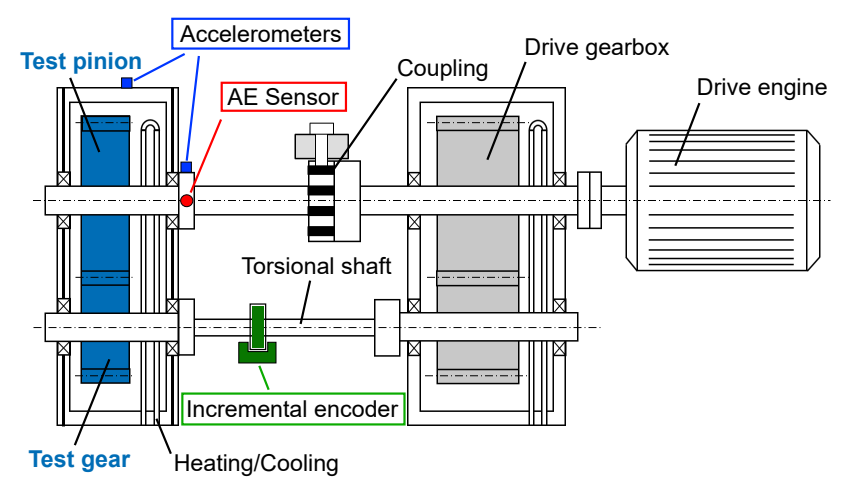

Fig. 4: Sensor instrumentation on the B2B test rig.

\section{Pitting classification system}

After the sensor data was acquired by the measurement system during the load capacity tests, the 10 second sensor data samples are processed and classified using a supportvector machine (SVM). The applied signal processing scheme is shown in figure 5 .

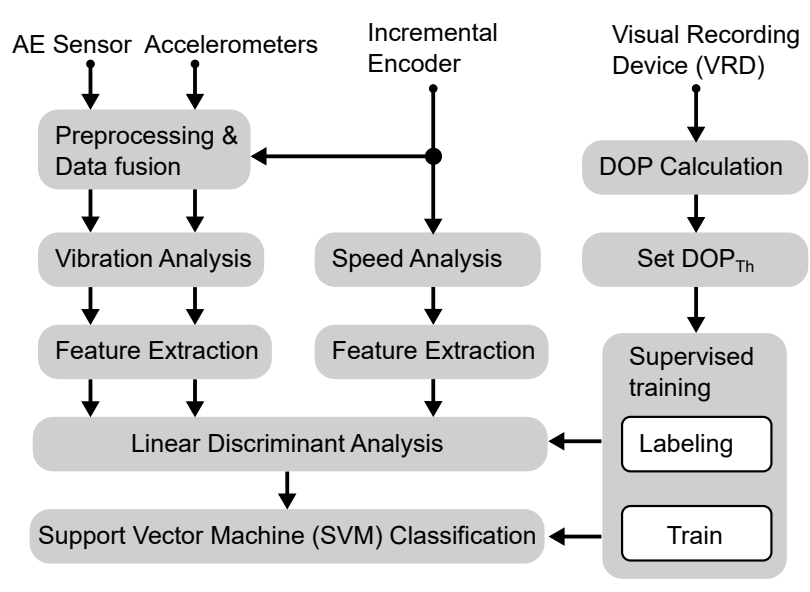

Fig. 5: Applied pitting classification scheme. 


\section{Data fusion \& analysis}

Before the feature extraction step is applied, the vibration data (accelerometer and AE sensor data) have to be preprocessed using different filtering methods. The data of the incremental encoder are fused with the data of the accelerometer and the AE sensor to enable the calculation of the order spectrum using a fast Fourier transform in the step vibration analysis. Further analyses such as wavelet analysis are performed to prepare the data for feature extraction.

\section{Feature extraction}

In the feature extraction step, statistical parameters of all sensors are first calculated from the four central moments of a probability distribution: mean, variance, skewness and kurtosis. Afterwards sensor-dependent features in the time domain, order domain and time-order domain are determined for each sensor.

Since pitting is expected to occur as locally distributed tooth flank damage, this stimulates an additional oscillation in the shaft order. This in turn leads to sidebands in the accelerometer signal of order one around the tooth mesh order and its harmonics, which is calculated from the product of the shaft rotation order and the number of teeth of the gear mounted on the shaft [5]. Therefore the magnitudes of the mentioned sidebands are extracted from the accelerometers order spectrum and normalized to the magnitudes of the gear mesh order and saved as features. In addition, a cepstrum analysis is performed to extract a feature from the quefrency region corresponding to the sidebands excited by pitting. Furthermore the residual signal is calculated by removing the shaft harmonics and gear mesh order and harmonics, and then various indicators such as FM0, FM4 are extracted from the residual signal. For more information see [12].

In addition, the RMS value of a high-pass filtered $\mathrm{AE}$ signal with a cut-off frequency at $20 \mathrm{kHz}$ is extracted from the AE sensor. Furthermore, the magnitudes of the shaft orders of the input shaft and the output shaft and their harmonics are extracted from the order spectrum of the incremental encoder signal and used as features.

\section{DOP calculation \& labeling}

To evaluate the extracted features and the classification results, the tooth flank images from the VRD are processed and the values $\mathrm{DOP}_{k}$ and $\mathrm{DOP}_{\mathrm{G}}$ are calculated. By setting a defined threshold value $\mathrm{DOP}_{\mathrm{Th}}$ for one of these two values, the extracted sample features are labeled by dividing them into two classes: (i) Class No pitting: data samples with relative pitting surface $<\mathrm{DOP}_{\mathrm{Th}}$

(ii) Class Pitting: data samples with relative pitting surface $\geq \mathrm{DOP}_{\mathrm{Th}}$

\section{Linear discriminant analysis}

The output of the feature extraction methods is a matrix of over one hundred features, with some of the features being correlated and the multivariate distribution of the classes does not provide optimal separability properties. The aim is to maximize the class separability of the extracted and labeled features, taking into account the interdependencies between the features to increase the classification accuracy of the classifier. The class separability criterion is defined as the ratio of the variance of the class mixture mean (between-class scatter) to the variance of samples around their respective class mean (within-class scatter) [4]. The criterion is maximized by applying a principal component analysis (PCA) to the covariance matrix of the within-class scatter, followed by a whitening of the diagonal entries of the covariance matrix and a PCA to the covariance matrix of the between-class scatter in order to maximize the distance between classes in the feature space.

\section{SVM classification}

The labeled and transformed feature space is forwarded to a support-vector machine (SVM). Using a training data set, the SVM constructs a hyperplane in a highdimensional subspace with the largest margin separating the two labeled feature classes. An SVM is used as a classifier because its high generalization capability makes it very effective in real applications. They have a high computational efficiency because their classification decision is based on only a few trained support vectors. Therefore this classifier can be used for real applications in the aviation industry, e.g. in a condition monitoring system of a PGB.

\section{Results}

This section presents the results of the load-capacity tests and the classification results generated by the proposed pitting classification scheme in figure 5. First, the test used to train the SVM classifier is discussed. At the end of this section, the classification results based on the measurement data of the second gears tested are presented. 


\subsection{Load-capacity test results}

Two test runs were carried out with two completely new test gearsets (Test Gear I \& Test Gear II) with one test pinion and one test gear per set. Since pitting occurred predominantly on one tooth of the test pinions, the $\mathrm{DOP}_{k}$ value was used to label the data samples.

The first test run with Test Gear I had a test duration of 310 hours $\left(55.8 \cdot 10^{6}\right.$ L.C.) and contains a total of 1104 data samples. The most significant pitting occurred on the $8^{\text {th }}$ tooth of test pinion with a $\mathrm{DOP}_{8}=3.3 \%$, see upper picture of figure 6 . The second test run with Test Gear II had a test duration of 410 hours ( $73.8 \cdot 10^{6}$ L.C.) and contains a total of 1371 data samples. The most significant pitting occurred on the $10^{\text {th }}$ tooth of test pinion with a $\mathrm{DOP}_{10}=7.5 \%$, see upper picture of figure 7 .

\subsection{SVM training}

The bottom picture of figure 6 shows the $\mathrm{DOP}_{8}$ pitting curve (blue) and an AE feature (red) for the first test run with Test Gear I. The AE feature is derived from the normalized high-frequency energy, for which the AE signal was high-pass filtered and then the RMS value of the filtered signal was calculated. The feature values show a high correlation with the $\mathrm{DOP}_{8}$ curve. This test run was used for training the SVM classifier and the $\mathrm{DOP}_{\mathrm{Th}}$ value was set to $0.7 \%$ for data labeling.

\subsection{Classification results}

The results from the second test run Test Gear II are plotted in figure 7 in a comparative manner like for the first test run and show that pitting occurred later on the concerned tooth flank than in the first test and lead to a higher slope of the pitting surface during the test.

The $\mathrm{DOP}_{\mathrm{Th}}=0.7 \%$ value is marked by a dashed line and acts as a comparable pitting severity value between the two test runs. The decisions of the SVM classifier between both classes (Pitting \& No pitting) are shown in the bottom picture of figure 7 . The results indicate that in the range before $34 \cdot 10^{6}$ L.C. and after $60 \cdot 10^{6}$ L.C. the classifier has the best accuracy. Many misclassifications (false positives) occur mainly in the range between $45 \cdot 10^{6}$ L.C. and $60 \cdot 10^{6}$ L.C.. It appears that the pitting damage in the second test run already at a lower $\mathrm{DOP}_{10}$ value leads to typical patterns in feature space on which the SVM classifier was trained to classify the data as pitting damage. One reason of the incorrect classifications

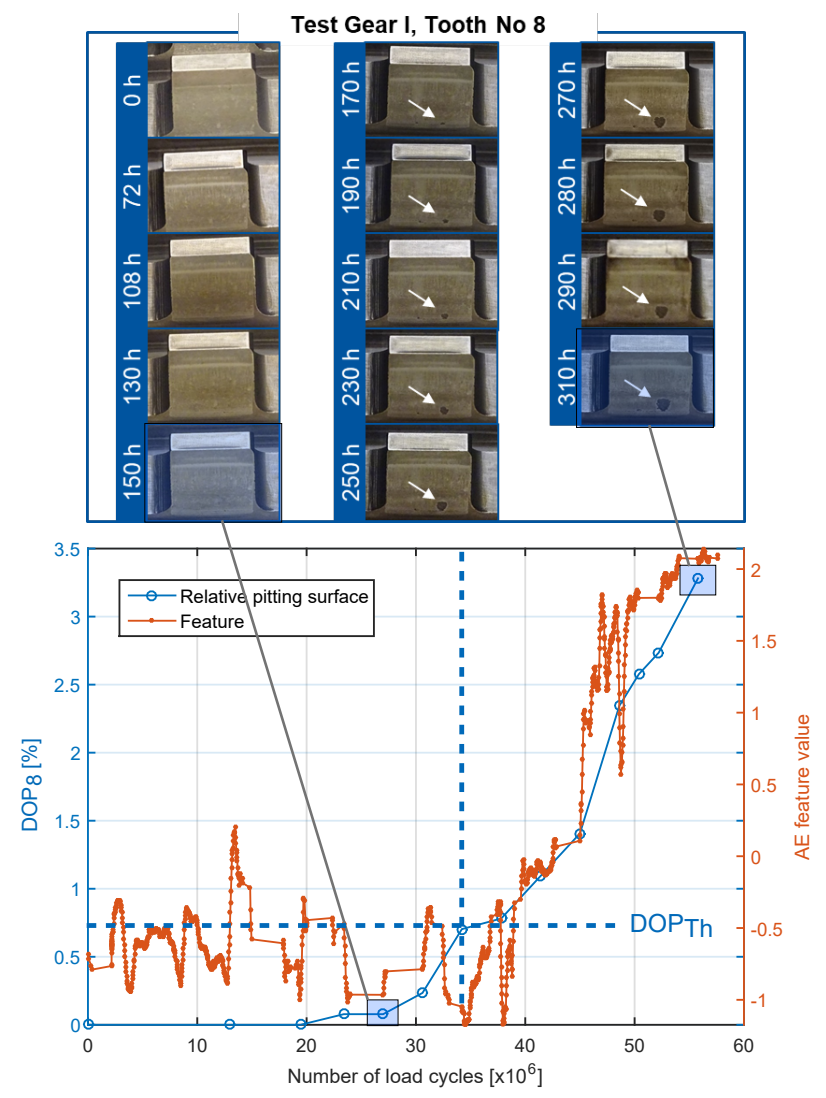

Fig. 6: Test results of Test Gear I used for SVM training.

of the SVM classifier in this range could be that the set DOP threshold value DOP $_{\mathrm{Th}}$ cannot easily be compared between the two test runs. However, this only leads to false positive decisions and would in this case even allow earlier detection of pitting damage due to a higher pitting sensitive of the SVM.

Figure 8 shows the confusion matrix, precision and recall and the $\mathrm{F}_{1}$-score [1], which allows an evaluation of the classifier. The results show that pitting with a pitting surface of more than $0.23 \%$ could be correctly classified and no false negative results occurred. This means that with a pitting surface greater than $0.23 \%$ the classifier has for the given test data a very high accuracy. The total $\mathrm{F}_{1}$-score has a low value, but this may be a reason for the not optimal $\mathrm{DOP}_{\mathrm{Th}}$ value chosen for the labeling of the classified data samples from Test Gear II.

\section{Conclusion and outlook}

The experiments have shown that the image acquisition of pitting growth during a test run gains huge benefit for providing evidence of selected features. The results also 


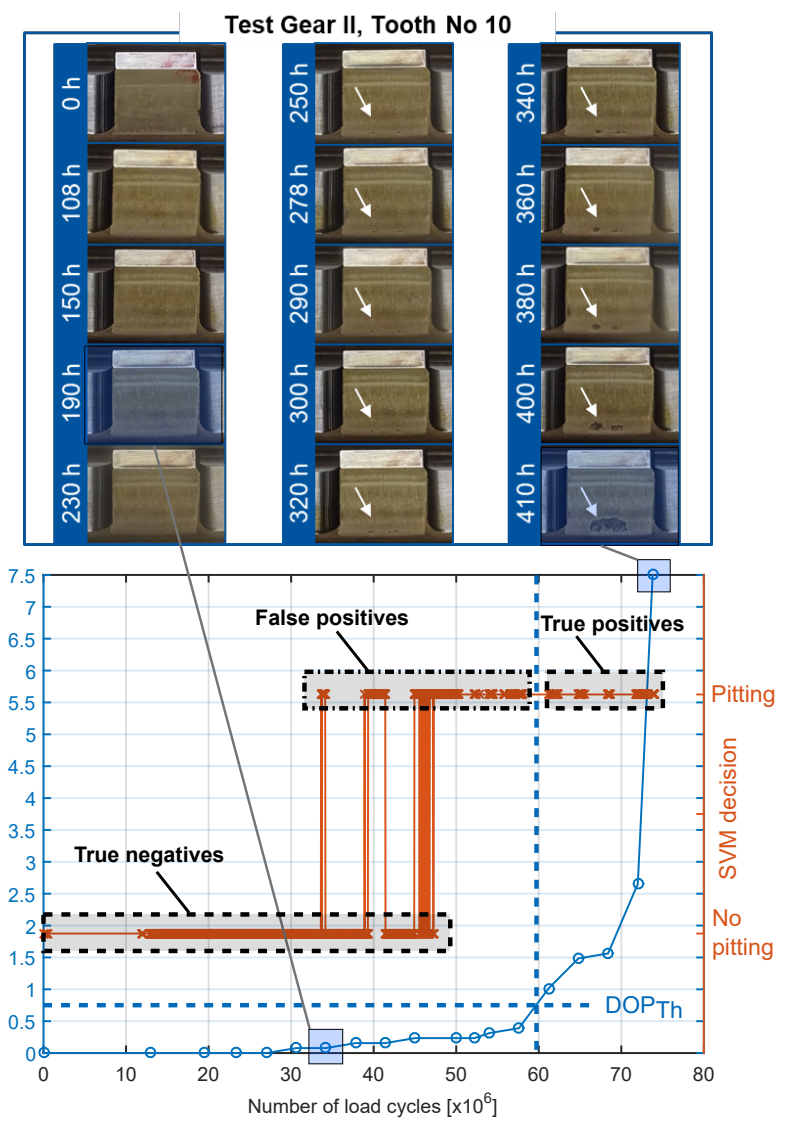

Fig. 7: Classification results using data samples from Test Gear II.

indicate that the pitting progress from a relative pitting surface of less than $1 \%$ on a single tooth can be detected by using acceleration and acoustic emission sensors and a support vector machine as a classifier.

In future work, the findings presented in this contribution should be incorporated into a lifetime prognosis in order to enable an estimation of the remaining lifetime of the gearbox. This could lead to a reduced progression of gear teeth degradation and enables further operation until scheduled or planned maintenance action. Also in general gearbox applications a sudden gearbox failure could be avoided by applying the proposed concept.

Acknowledgement: Thanks to Rolls-Royce Germany for permission to publish the results.

\section{References}

[1] H. M. Blanken, A. P. de Vries, H. E. Blok, and L. Feng. Multimedia Retrieval. Data-Centric Systems and Applications. Springer Berlin Heidelberg, 2007. ISBN 9783540728955.

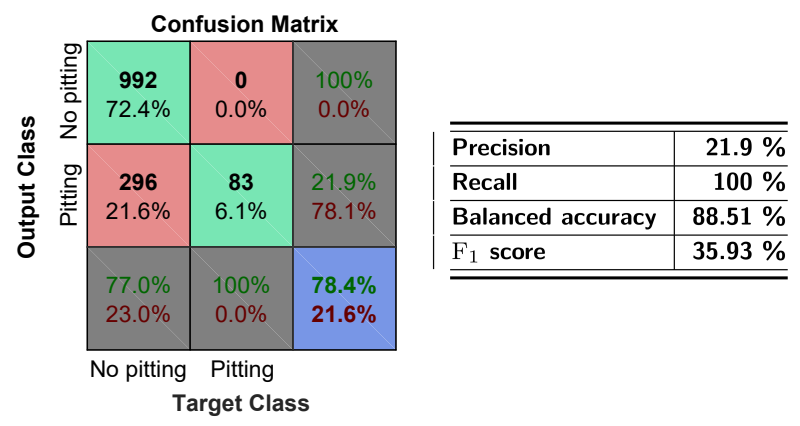

Fig. 8: Confusion matrix and classifier evaluation results.

[2] DIN Deutsches Institut für Normung e. V. DIN ISO 14635: Zahnräder - FZG-Prüfverfahren, Januar 2010.

[3] EASA, European Environment Agency. European aviation environmental report 2019, 2019.

[4] K. Fukunaga. Introduction to statistical pattern recognition. Computer science and scientific computing. Academic Press, San Diego, 2. edition, 2009. ISBN 0-12-269851-7.

[5] M. Grzeszkowski, C. Gühmann, P. Scholzen, C. Löpenhaus, S. Nowoisky, and G. Kappmeyer. Experimental study on the pitting detection capabilities for spur gears using acoustic emission and vibration analysis methods. In Gear Technology, volume 36, No. 2, pages 48-57. Randall Publications LLC, Elk Grove Village, Illinois, USA, 2019.

[6] R. Medina, M. Cerrada, D. Cabrera, R.-V. Sanchez, C. Li, and J. V. D. Oliveira. Deep learning-based gear pitting severity assessment using acoustic emission, vibration and currents signals. In 2019 Prognostics and System Health Management Conference (PHM-Paris), pages 210-216. IEEE, 02.05.2019 - 05.05.2019. ISBN 978-1-7281-0329-7. 10.1109/PHM-Paris.2019.00042.

[7] Rolls-Royce. Rolls-royce sets new aerospace record with ultrafan $\AA$ power gearbox, 2017. URL https://www.rollsroyce.com/media/our-stories/press-releases/2017/04-092017-rr-sets-new-aerospace-record-with-ultrafan-powergearbox.aspx.

[8] C. K. Tan, P. Irving, and D. Mba. A comparative experimental study on the diagnostic and prognostic capabilities of acoustics emission, vibration and spectrometric oil analysis for spur gears. Mechanical Systems and Signal Processing, 21(1):208-233, 2007. ISSN 08883270. 10.1016/j.ymssp.2005.09.015.

[9] T. Tobie. Zur Grübchen- und Zahnfußtragfähigkeit einsatzgehärteter Zahnräder: Einflüsse aus Einsatzhärtungstiefe, Wärmebehandlung und Fertigung bei unterschiedlicher Baugröße. FZG, 2001.

[10] T. Tobie and P. Matt. Empfehlungen zur Vereinheitlichung von Tragfähigkeitsversuchen an vergüteten und gehärteten Zylinderrädern. FVA-Richtlinie Nr. 563 I, 2012.

[11] B. van den Heuvel. Schwingungstechnische Zustandsüberwachung von Antriebssträngen in Windenergieanlagen, 2015.

[12] P. Vecer, M. Kreidl, and R. Smid. Condition indicators for gearbox condition monitoring systems. Acta Polytechnica Vol. 45 No. 6/2005, pages 1-6, 2005. 10.1002/0471741833.ch1. 